Document downloaded from:

http://hdl.handle.net/10251/136494

This paper must be cited as:

Andruskiewicz, P.; Najt, P.; Durrett, R.; Payri, R. (2018). Assessing the capability of conventional in-cylinder insulation materials in achieving temperature swing engine performance benefits. International Journal of Engine Research. 19(6):599-612. https://doi.org/10.1177/1468087417729254

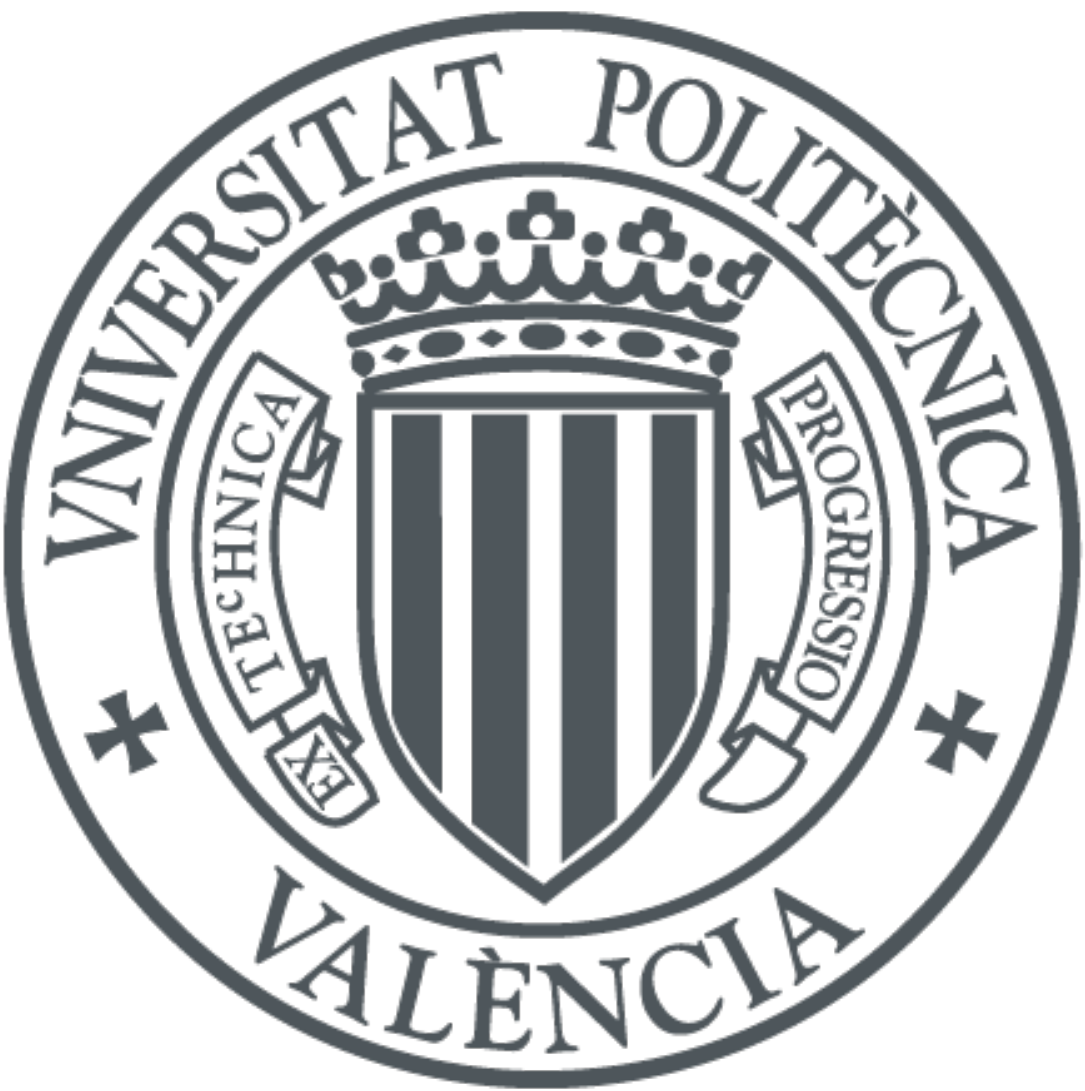

The final publication is available at

https://doi.org/10.1177/1468087417729254

Copyright SAGE Publications

Additional Information 


\title{
Assessing the Capability of Conventional In-Cylinder Insulation Materials in Achieving Temperature-Swing Engine Performance Benefits
}

\author{
Peter Andruskiewicz, Paul Najt, Russell Durrett - General Motors \\ R\&D, PSR Lab
}

\section{Raul Payri - Universitat Politècnica de València, CMT Motores Termicos}

\section{Abstract}

Materials that enable wall-temperature-swing to follow the gas temperature throughout a reciprocating internal combustion engine cycle promise the greatest benefits from incylinder insulation without detriments to volumetric efficiency or fuel autoignition behavior. An anisotropic barium-neodymium-titanate (BNT) insulation was selected as a promising off-the-shelf material to begin investigating temperature swing characteristics while maintaining adequate strength and adherence to the aluminum components it was applied to. Experimental analysis showed that permeable porosity within the BNT coating resulted in increased heat losses despite thermal insulation, fuel absorption losses, and a reduction in compression ratio. Additionally, the thickest coating suffered severe degradation throughout testing. Any potential benefits of temperature-swing insulation were dominated by these losses, emphasizing the need to maintain a sealed coating surface.

\section{Introduction}

Increasing emissions and fuel consumption standards across the world are driving engine and vehicle manufacturers to improve overall vehicle efficiency and environmental impact as much as possible, while the competitive nature of the market ensures that solutions must be cost-effective. Two of the megatrends in engine design to address these constraints are the moves to downsize and to downspeed light-duty engines, effectively spinning a smaller engine more slowly at a higher specific load to minimize pumping and frictional losses in everyday usage. The limits to these trends are generally related to high in-cylinder temperatures and pressures, low-load torque capacity dictated by the boosting device used, engine knock and fuel enrichment in gasoline engines, and increased emissions and high-speed load potential for diesel engines. In this environment, incylinder thermal management could prove to be a very important tool for further improving the efficiency and environmental friendliness of the internal combustion engine.

Over the range of speeds and loads encountered in passenger vehicle use, approximately $30 \%$ of the fuel energy leaves the cylinder through heat transfer to the combustion chamber walls and another 5-10\% through the exhaust port walls. This energy is 
transferred to the coolant at a relatively low temperature, and thus has low availability for reclamation. Preventing this energy loss from the hot combustion gasses could increase the useful crank work that the gas performs directly, as well as to improve the function of devices such as turbochargers, exhaust compounding, and aftertreatment catalysts that rely on exhaust energy to function. The need for engine cooling drives further vehiclelevel losses such as larger coolant pumps, higher coolant pressures and flows, and larger heat exchangers with greater aerodynamic drag. Additionally, thermal barriers act as component thermal protection to enable greater specific output, aiding further downsizing and downspeeding. There has been considerable recent activity to minimize heat losses and improve engine performance through in-cylinder insulation (1) (2) (3) (4) (5) (6)

Historically, many authors have attempted to use in-cylinder insulation for engine performance benefits. Some of the pioneering works were performed by TACOM for military vehicles, emphasizing the elimination of the engine cooling system, and the tactical benefits provided by improved efficiency (7). Many of the early attempts used monolithic ceramics (8) (9) such as silicon carbide (10), partially-stabilized zirconia (11), and silicon nitride (12), as well as the removal of coolant (13) and plasma-sprayed zirconia (14). A significant reduction in heat transfer was reported by most of these sources, but any improvements in brake output required an energy recovery device in the exhaust such as a turbocharger or turbine compounding system. Naturally aspirated results generally showed no benefit to piston work; all of the energy redirected by the insulation appeared in the exhaust. Volumetric efficiency (VE) was negatively impacted by between $3-10 \%$ depending on the level of insulation, forcing lower load or richer incylinder conditions. Turbochargers could recover some of the excess energy in the exhaust to overcome the VE penalty and to provide a benefit in brake work, but that benefit was derived mostly from the pumping loop. Turbocompounding continued this trend further, allowing the recovery of more work at high loads back to the crankshaft.

It was recognized relatively early that simply increasing the wall temperature to achieve zero net heat transfer would not result in significant engine performance gains due to the reduction in volumetric efficiency and increase in compression work. Wallace et. al. (15) analytically investigated the difference between isothermal wall temperature and instantaneously adiabatic conditions, and discovered a large difference in indicated efficiency and air delivery ratio between these cases. Modeling studies deriving from this analysis (16) highlighted the benefits of an insulating wall of sufficiently low heat capacity such that its surface temperature tracked the gas temperature throughout the cycle, approximating the adiabatic case. This enabled large reductions in the peak heat transfer rate while allowing the wall temperature to fall with the gas temperature during the intake and compression strokes to avoid detrimentally affecting VE. Work required for compression was reduced, enabling a brake benefit even with naturally aspirated engines. Further experimental studies with air-gap-insulation (17) showed that the presence of metal mass over the air gap negated the temperature swing properties of the air gap, and emphasized the importance of the properties of the wall surface. Other researchers confirmed the same basic findings, emphasizing the importance of wall temperature swing in insulation performance (18) (19) (20) (21). 
The amount of surface temperature swing is dictated by the bulk material properties of the material in contact with the gas. Figure 1 depicts lines representing the surface temperature swing predicted for a wide range of material properties given a fixed set of thermodynamic conditions in the upper left plot. Lower thermal conductivity and lower volumetric heat capacity both increase the surface temperature swing, but is also a strong function of engine operating parameters such as load, combustion phasing, engine speed, and any others that affect the gas temperature, heat transfer coefficient, and time for heat transfer. The other plots in this figure represent the estimated effects on the engine operation when hypothetical materials \#1 - 3 were applied over metal-like walls, and the thickness of the underlying walls were adjusted to achieve the same total thermal resistance. The baseline was also metal-like, but at the same total thickness as case \#1. As described in the reference, large amounts of temperature swing result in a selective reduction of heat transfer during combustion and expansion where the energy can be captured by the piston. Temperature swing allows the surface to cool back to the baseline level prior to the intake stroke, so volumetric efficiency is not hurt. Similarly, the wall temperatures during compression are much cooler than even the baseline, and therefore less piston work is required during compression.
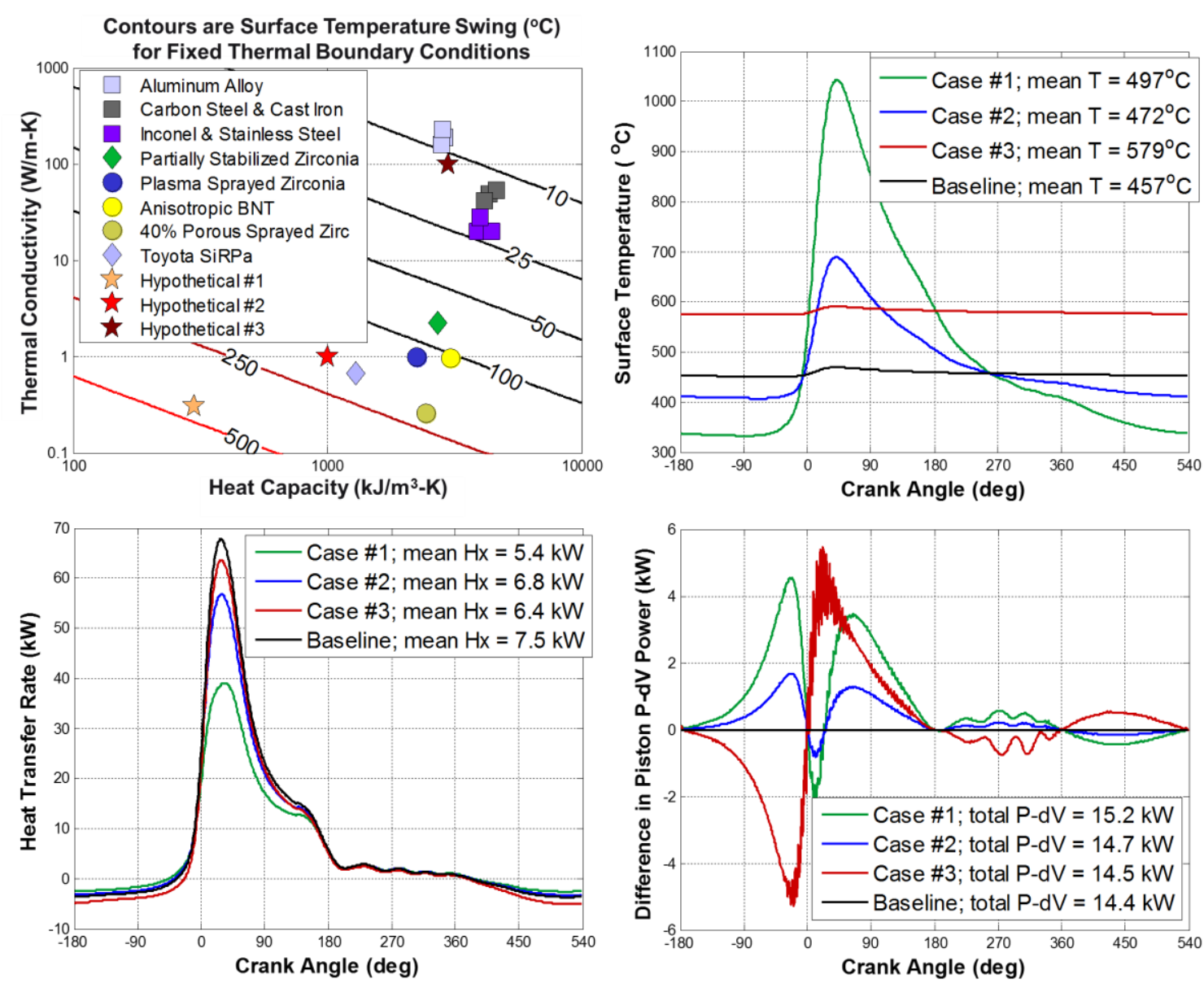

Figure 1: Material Properties, Temperature Swings, and Engine Effects from Reference (1) 
The thickness of the insulation plays a critical role in balancing heat losses off the front and back of the coating, to ensure that the surface temperature of the insulation can fall below the temperature of the un-insulated component temperature. A critical depth $1 \%$ is defined as a function of the material properties and frequency of the driving heat flux as the depth into the material at which the temperature swing decays to $1 \%$ of the swing at the surface. Ideal insulating thickness for reciprocating internal combustion engines is generally about $25 \%$ of the depth $1 \%$ due to the locations of maximum and minimum heat flux throughout the cycle, and the temperature waves through the coating that are established. This parameter is critical for properly designing coatings for effective temperature-swing insulation, as demonstrated by Andruskiewicz et. al. (1).

$$
\Delta T \sim \frac{1}{\sqrt{\rho \times c \times k}}
$$

Equation 1

In general, the surface temperature swing will be related to the material properties through the relation proposed by Assanis (20) in Equation 1. The volumetric heat capacity " $\rho \times c$ " of a bulk material is a function of the composition (mass heat capacity “ $c$ "), and of the density of the bulk material " $\rho$ ". The effective thermal conductivity " $k$ " is dependent on the material structure, types of elemental bonds, and larger-scale geometric features such as the effective cross-section perpendicular to conduction and path length in the direction of conduction. A reduction in bulk density through the introduction of voids in the solid material will both directly affect the volumetric heat capacity as well as the conductivity by decreasing the cross-section of solid material. Since air has a volumetric heat capacity of approximately $1 / 1000^{\text {th }}$ and a thermal conductivity of $1 / 100^{\text {th }}$ of any of the solid materials shown, the addition of air into a bulk material through porosity can greatly improve the thermal properties necessary for temperature swing. Porosity introduced by spray application of ceramics such as plasma-sprayed zirconia, or engineered into the structure like SiRPa (4) can have a much larger impact on both the thermal conductivity and heat capacity due to the void volume. This approach has been measured to demonstrate much larger temperature swings than conventional materials, resulting in gains in brake work (3).

\section{Experimental Apparatus}

The experiments performed in this work were carried out in a direct-injected single cylinder gasoline spark-ignition (SI) engine with a geometry shown in Table 1. The combustion chamber was similar to production designs, utilizing a central direct injector to provide even fuel distribution. The piston surface was contoured to enable a high compression ratio while still allowing for a central bowl for combustion near TDC. Variable cam phasing was employed to mimic engine breathing events employed in production engines for increased efficiency.

Precise control of the engine was provided by a bespoke system, allowing complete freedom of ignition, injection, and cam timing. Air flow was provided by a critical flow orifice system which enabled the calculation of exact air mass, while fuel flow was directly measured through two devices using different principles and confirmed with 
emissions measurements coupled with the air flow. Emissions were measured with a Horiba MEXA-series bench with analyzers for unburned hydrocarbons, $\mathrm{CO}, \mathrm{CO}_{2}, \mathrm{O}_{2}$, and oxides of nitrogen $\left(\mathrm{NO}_{\mathrm{x}}\right)$. In-cylinder gas pressure was measured with a Kistler $6125 \mathrm{~A}$ piezoelectric pressure sensor, associated charge amplifier, and flame arrestor to mitigate thermal shock.

Table 1: Engine Geometry

\begin{tabular}{|r|c|}
\hline Bore & $86 \mathrm{~mm}$ \\
\hline Stroke & $94.6 \mathrm{~mm}$ \\
\hline Comp. Ratio & 12.0 \\
\hline Combustion Type & $\mathrm{SI}$ \\
\hline Chamber Type & 4-valve, Pent-roof \\
\hline Intake Duration & $260^{\circ}$ \\
\hline Exhaust Duration & $230^{\circ}$ \\
\hline
\end{tabular}

Two pistons of each coating thickness were tested in the single-cylinder experimental engine. Each piston was run for a total of over 10 hours at varying speeds and loads prior to performing the measurements presented herein in order to reach a stabilized condition for the coating, piston sealing rings, and in-cylinder deposits. An ignition timing sweep was then recorded at three load points at 2000 RPM, defined by the fueling rates of 10.5, 21 , and $31 \mathrm{mg} /$ cycle. These aligned with roughly 3 bar, 6 bar, and 9 bar IMEP, evenly sweeping operation of a naturally aspirated SI engine. The testing was conducted over multiple days, with a motoring and firing control point taken at the beginning of each ignition timing sweep, and a motoring point taken following the sweep. These control points were used to ensure data integrity and repeatability between tests and hardware sets, considering how the differences in hardware would affect the control points. Representative measurements at each load for each coating were chosen for subsequent analysis.

A barium-neodymium-titanate $\left(\mathrm{BNT}-\mathrm{BaNd}_{2} \mathrm{Ti}_{3} \mathrm{O}_{10}\right)$ material was chosen for experimentation due to its unique anisotropic structure when plasma-sprayed. BNT is a layered perovskite that has a crystalline structure with planes of low thermal conductivity within the material. The angle of these planes can be tailored during the application process to match the coefficient of thermal expansion between the coating and the metal substrate to promote better bonding and reduce thermal stresses as the component heats and cools. The thermal conductivity of the plasma-sprayed BNT material varied between 0.8 and $1.2 \mathrm{~W} / \mathrm{m}-\mathrm{K}$ depending on the orientation of the insulating planes to the measurement, while the heat capacity was comparable to plasma-sprayed zirconia coatings. BNT had also shown durability as an insulating coating high-temperature oxidizing environments (22). The material properties of BNT are not exceptional with respect to temperature swing, but it was important to investigate the currently available options to gain experience in testing procedures and providing a baseline for further material development. The anisotropic nature of the coating was also theorized to have some benefits to temperature swing by essentially sequestering a small amount of mass at the surface insulated by the lower conductivity planes beneath it, although these potential benefits were not explicitly analyzed. 
Simulation of BNT as an in-cylinder insulating material was performed, and the critical depth $_{1 \%}$ at 2000 RPM was calculated to be $300 \mu \mathrm{m}$. Coating depths of 300, 600 and $1200 \mu \mathrm{m}$ were chosen for experimental testing to attempt to record a range of reductions in net heat transfer at varying average surface temperatures. These target thicknesses were cut into the piston face, creating a pocket that the BNT could be applied into to preserve compression ratio and piston surface position. The actual coating thicknesses were measured before and after testing, and averaged to 230, 500, and $1000 \mu \mathrm{m}$ respectively, representing $77 \%, 167 \%$, and $333 \%$ of BNT's depth $1 \%$. These thicknesses are greater than the ideal $25 \%$ of the depth $1 \%$ identified in previous work (1), but the pistons were coated prior to the conclusion of the modeling work. Nevertheless, they could still be useful in confirming the trends identified by the model. Insulation was only added to the center of the piston crown extending to $5 \mathrm{~mm}$ from the piston edge in an effort to limit piston or bore scuffing if the coating failed. The bore, head surface, and valves all remained un-coated.

\section{Analytic Methodology}

A 0-dimensional commercially available engine thermodynamic model was used to simulate the single-cylinder SI experimental engine and extend the learnings available through experimentation. Thermodynamic model predictions including all sub-models were calibrated to experimental data. The combustion chamber itself models the gas as a single bulk zone, for consistency with the analysis of experimental results. Combustion is prescribed by the experimental heat release curve, converting molecules from the unburned to the burned mixture. Gas properties are solved for based on the concentrations of basic molecules such as $\mathrm{N}_{2}, \mathrm{O}_{2}, \mathrm{CO}_{2}, \mathrm{CO}, \mathrm{H}_{2} \mathrm{O}, \mathrm{H}_{2}$, and Fuel.

Intake and exhaust flow was modeled as a series of sealed pipes and volumes to capture wave dynamics in the manifolds and ports. The geometry of the model was made to match the physical engine as closely as possible up until large settling tanks for the intake and exhaust systems to capture wave dynamics. Boundary conditions were taken from experimental data, with the intake pressure varied to produce the same fresh air flow as recorded in the data. Combustion was prescribed based on the normalized experimental heat release rate and combustion efficiency from emissions measurements. Heat transfer was modelled using a continuous form of the Woschni equations (23), driven by the need to avoid discontinuous steps in heat transfer rate that would produce unrealistic effects in the wall temperatures. A multiplier on the convection coefficient was calculated from experimental data through the need to enforce energy closure during the closed portion of the cycle.

Energy closure was enforced by ensuring that the difference between the fuel chemical energy, minus combustion inefficiencies, and the net heat release calculated from the cylinder pressure must be equal to the total heat losses incurred. Porosity heat losses were calculated from a porosity volume and wall temperature, assuming that mass flow entering the porosity volume would instantaneously assume the wall temperature, losing the difference in energy in the process. This assumption is consistent with common 
assumptions for crevice heat losses, as outlined in (24). The surface to volume ratio of porosity within permeable coatings is at least an order of magnitude higher than crevice volumes, further supporting the validity of this assumption. Crevice volumes for each coating thickness were calculated from their motoring traces, noting the difference in effective compression ratio in comparison to the expected decrease.

A 2-dimensional implicit finite-element Thermal Wall Temperature Swing (TWTS) model was written to interface with the engine thermodynamic model and the experimental data analysis. This model was written to enable analysis of the wall temperature swing based upon the sources of heat transfer from the combustion gas, the thermal properties of the materials in the walls, and the physical structure of the engine. It is detailed primarily in the dimension outward from the combustion chamber in order to capture area-averaged wall temperature swing effects throughout the cycle. Detail along the combustion chamber surface was minimized, in accordance with the generalizations implicit in the Woschni convection equations, and in the single-zone temperature analysis assumptions from experimental data analysis and analytical modeling.

The combustion chamber surface was divided into five components; piston, bore wall, head, intake valves, and exhaust valves. Specific geometries, surface areas, and layered materials for each of these components were specified, assuming radial symmetry of the combustion chamber. Heat transfer from the combustion gas was dictated by the Woschni convection correlations, while heat transfer between structures and to thermal sinks (oil and coolant) were specified through individual convection coefficients. Calibration of these convection coefficients was performed utilizing measurements in literature (25) (26) (27) (28) in addition to unique measurements taken through similar means in the experimental study. More details on this model are in prior publications by the author (1).

\section{Results and Analysis}

\section{Experimental Results}

Experimental results were measured using the anisotropic BNT coatings applied to pistons at target thicknesses of 300, $600 \& 1200 \mu \mathrm{m}$. Actual thicknesses were measured at $230,500 \& 1000 \mu \mathrm{m}$, so a reduction in compression ratio (CR) with coating thickness was expected. However, the measured drop in $\mathrm{CR}$ at the motoring control point was considerably more than expected or measured through static fluid displacement in a test fixture used to measure clearance volume changes for piston surfaces, as shown in Figure 2. Solid lines were taken prior to each variable sweep, while dashed lines were taken afterwards. Motoring compression ratio and piston-top clearance volume measurements were repeated multiple times through different engine builds using multiple pistons with the same coating thickness. It was speculated that the BNT coating was porous and permeable, that hot compressed air could more easily penetrate the coating than roomtemperature water used in the piston surface test fixture, and that the motoring compression ratio most closely reflected the true TDC volume.

The difference between the expected TDC volume and the motoring TDC volume was assumed to be the porous volume within the BNT coating. This assumption is critical to 
the results presented in this work, and was carefully made after re-processing the data with a wide variety of other assumptions and comparing the results to other measured parameters. Ultimately, the assumptions presented here were compared to the measured heat flux at the cylinder head surface, a rough system-level energy balance using the measured coolant temperatures and flow rates around the cylinder head and block, the shape of the gross heat release during the closed portion of the cycle, and the energy multipliers estimated compared to historical data and other builds of the same engine.

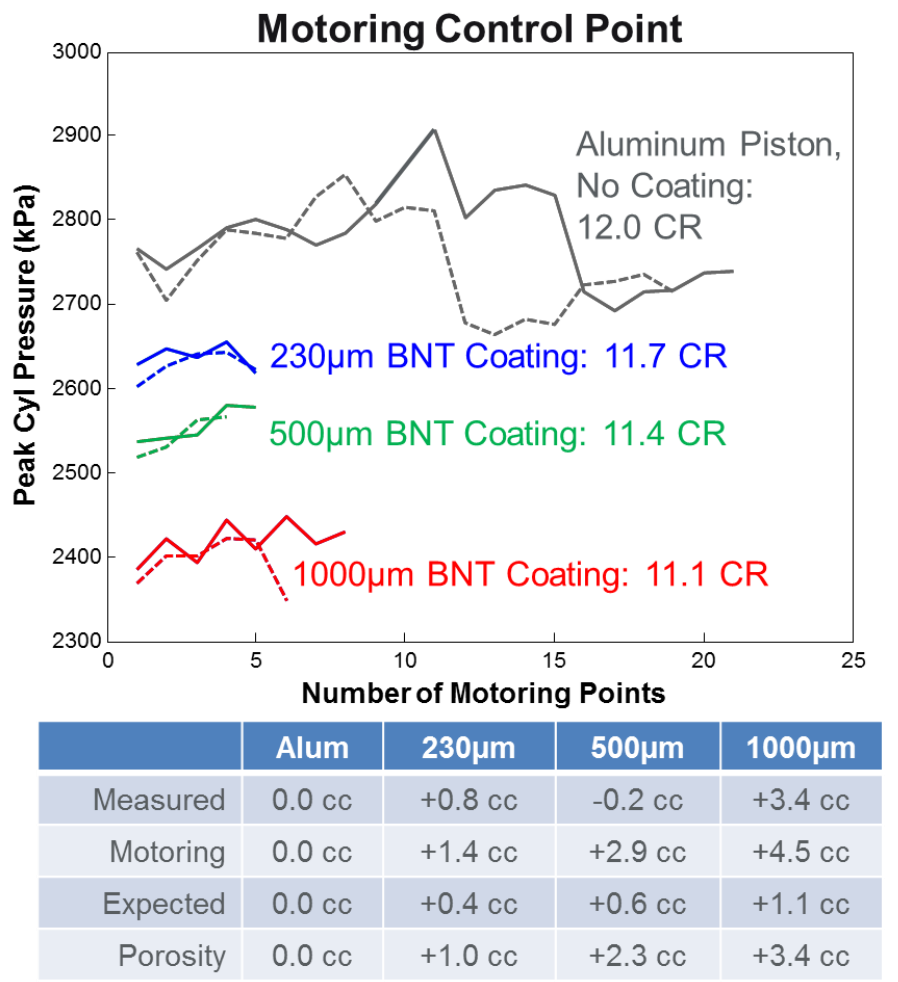

Figure 2: Reduction in Compression Ratio and Increase in Clearance Volume with Coating Thickness

Porosity of the coating was modeled in data analysis using the crevice model described previously as a sub-volume of the combustion chamber sharing the same pressure, but at the wall temperature. As gas pressure and temperature in the combustion chamber increased, mass was pushed into the coating porosity volume which was cooler and thus at a higher density. Heat loss from the gas entering the porosity volume was calculated using the assumption that the entering gas instantaneously reached the temperature of the porosity, which was justified by the estimated pore size and surface to volume ratio of the porosity. Heat was also transferred between the walls and the gas as the walls changed temperature throughout the cycle, forcing the gas to follow. Heat transfer to the porosity from these two sources were tracked and applied to the top node in the piston coating to simulate their effects on surface temperature. Wall temperature for the porosity was estimated as the thickness-averaged temperature of the BNT coating. It was necessary to use both this porosity model and the wall temperature solver to get physically possible results. Without using both the wall thermal model and the porosity model, non-real solutions were generated for many of the points with zero or negative convection, or 
compression ratios that varied with load and speed were required to maintain believable heat release curves.

The results of this heat release analysis using the porosity and thermal models are shown in Figure 3. All three coating thicknesses were analyzed alongside the un-coated piston at three loads and 2000 RPM. Combustion phasing at 50\% mass fraction burned (CA50) for all points at each load was matched as best as possible, although knock prevented the thickest coating from duplicating the combustion timing of the other cases at the highest load. The energy closure multiplier $(\alpha)$ applied to the convection coefficient is displayed in the legend for all datasets.

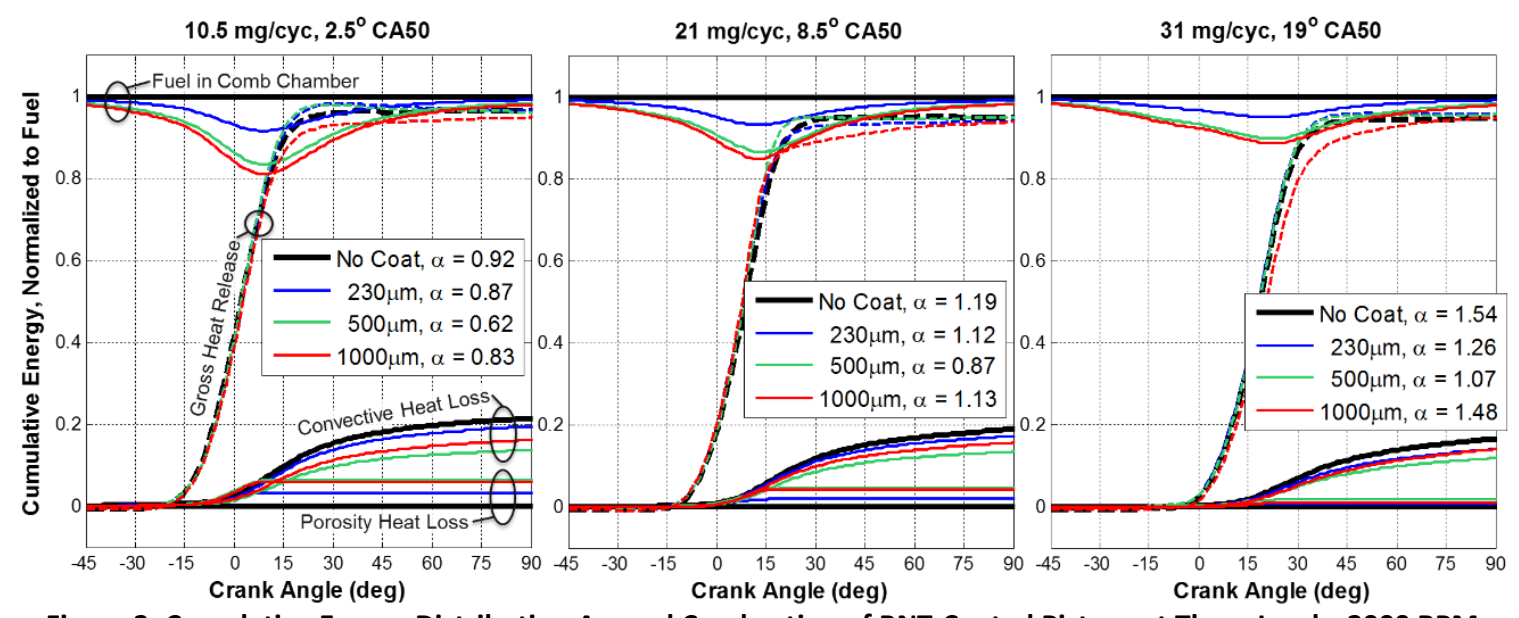

Figure 3: Cumulative Energy Distribution Around Combustion of BNT-Coated Pistons at Three Loads, 2000 RPM

At the low and mid-load points, the energy closure multiplier was very similar for the uncoated, 230 and $1000 \mu \mathrm{m}$ thickness coatings. The $500 \mu \mathrm{m}$ coating consistently showed a 20-30\% lower energy closure multiplier and total convective heat loss than the other coating thicknesses without showing a significant difference in the measurements of the heat flux probe or thermal energy rejected to the head or cylinder liner coolant. Additionally, this coating consistently showed a stronger late burn, with earlier CA90 timings than would be expected from the permeable porosity volume. Data points with the $500 \mu \mathrm{m}$ coating were the only ones in which the cumulative gross heat release significantly exceeded the fuel energy present in the combustion chamber, assuming that the fuel energy was homogeneously distributed amongst the total in-cylinder mass.

It is speculated that the $500 \mu \mathrm{m}$ coating may have been less permeable than the others to liquid fuel, which could have kept more fuel from entering the coating and enriched the mixture in the combustion chamber, promoting stronger late burns and lowering losses due to combustion phasing. This could also explain the negligible difference in clearance volume measured between the $500 \mu \mathrm{m}$ coated and the uncoated piston in the fluid displacement test results presented in Figure 2. Furthermore, this would imply that the calculated porosity losses for the $500 \mu \mathrm{m}$ coating using the assumptions about porosity volume derived from motoring listed above are higher than in reality, to which the energy balance responds by reducing the convection energy closure multiplier predicted. 
Conversely, the $1000 \mu \mathrm{m}$ coating consistently had the slowest late burn rate despite having very similar early and bulk combustion to the other cases, which could be due to more fuel mass getting trapped in the greater porosity volume in addition to substantial porosity heat losses. This coating had cumulative heat losses less than the $230 \mu \mathrm{m}$ and uncoated pistons, but had the combined heat and porosity losses on par with the $500 \mu \mathrm{m}$ coating despite having considerably hotter surface temperatures. As discussed above, the $500 \mu \mathrm{m}$ coating may have underestimated convection losses due to overestimation of its porosity losses, which result in the $1000 \mu \mathrm{m}$ coating appearing out of order. Ultimately, the addition of insulating coatings for any of these pistons did not result in a decrease in total heat losses to the piston from convection and porosity.
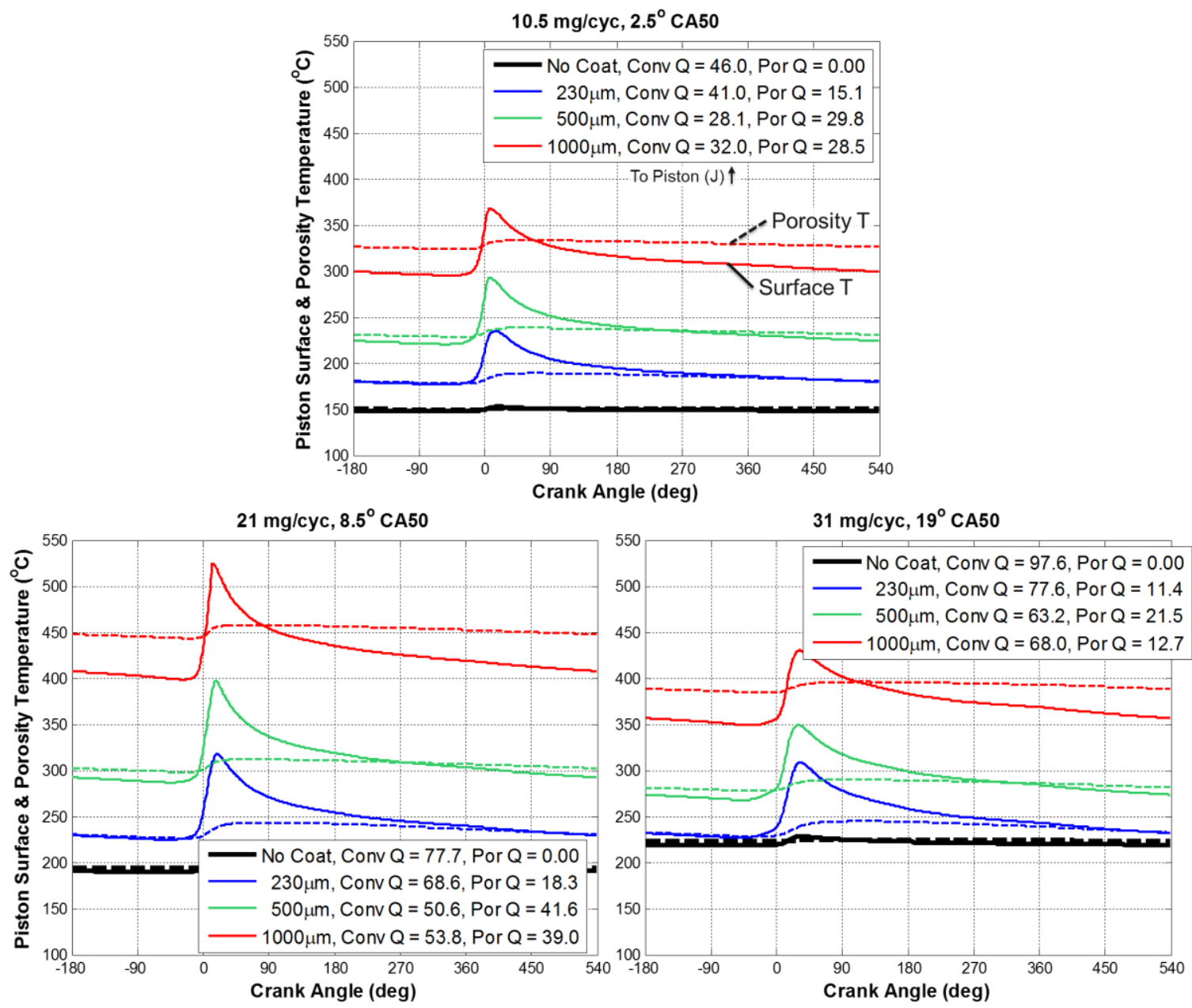

Figure 4: Predicted Piston Surface and Porosity Temperatures

The predicted piston surface and porosity wall temperatures are shown for all cases in Figure 4 as solid and dashed lines, respectively. The surface temperature for the piston is area-averaged between the coated center and the aluminum outside ring exposed to the gas, while the porosity temperature is thickness averaged throughout the depth of the coating but does not include the exposed aluminum ring. The porosity temperature is significantly damped because of this averaging and the effects of phase lag and decay of the temperature swing as depth into the coating surface increases. The porosity 
temperature is higher than the average surface temperature for the thickest coating since the surface temperature is area-weighted between the coated center portion and the uncoated aluminum outer ring, which pulls down the surface average the most for the thickest coating. Comparatively, the porosity temperature only includes the coating and is thus hotter for the thickest coating. The total heat energy transferred to the piston through convection and through porosity losses are listed for each data point in the legend.

As load increases, the temperatures increase for all coating thicknesses except for $1000 \mu \mathrm{m}$, which falls by $50^{\circ} \mathrm{C}$ between 21 and $31 \mathrm{mg}$ fuel/cycle. Although convection to the piston increases, the porosity losses for the $1000 \mu \mathrm{m}$ coating fall by $2 / 3 \mathrm{rds}$ between these two conditions, resulting in a net reduction in heat transfer of $13 \%$. Other coatings also see a large decrease in porosity losses at the highest load, but convective losses increase at a greater rate.

Similarly, the temperature swing is greatest at the $21 \mathrm{mg}$ fueling point, primarily due to the largest porosity losses at this load. The porosity losses are much more abrupt than convection losses, as shown in Figure 5. These losses are calculated when gas enters the porous volume and changes temperature to match the porosity temperature, and when the porosity bulk temperature changes as a function of piston coating heating and cooling. Energy is not transferred as gas leaves the porous volume. Therefore, the biggest contribution to porosity heat losses is when hot gas is driven into the relatively cooler, denser porous volume through compression and combustion, which takes the shape of an impulse leading up to and through the bulk of combustion near TDC. The resulting porosity losses introduce a sharp increase in the surface temperature of the coating. At lower loads, there is less heat loss overall to drive a temperature swing, and at higher loads the reduction in porosity losses coupled with the combustion phasing retard necessary to avoid knock serve to dull the temperature swing peakiness.
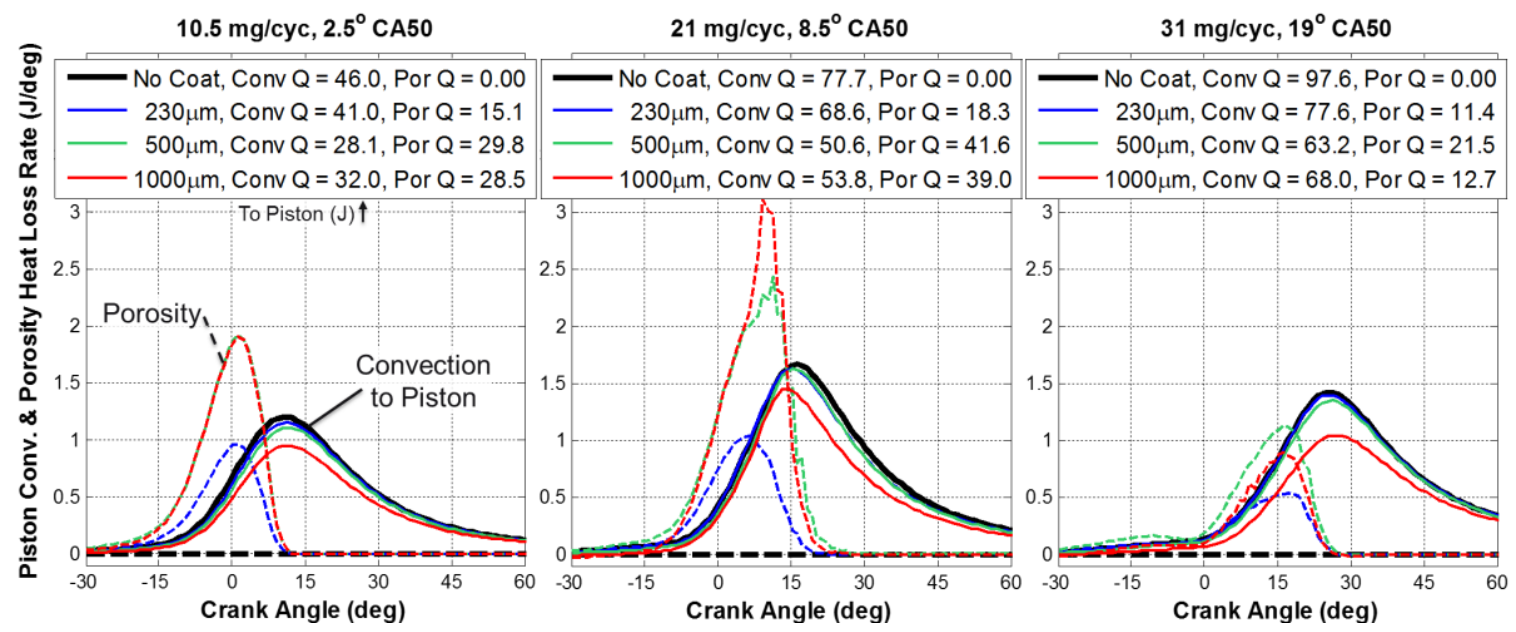

Figure 5: Piston Convective and Porosity Heat Losses

At low and mid-loads, the peak porosity losses rival convection for the two thickest coatings as shown in Figure 5. The 500 and $1000 \mu \mathrm{m}$ coating thicknesses experience similar peak and total porosity losses at low and mid-loads despite the $1000 \mu \mathrm{m}$ coating having $50 \%$ more porosity volume because it is also at a hotter temperature. Hotter 
coating temperatures limit porosity heat losses by reducing the difference in temperature between the coating and the gas, as well as decreasing the density and therefore mass of gas that can be held within the porosity volume at a given temperature. The porosity losses end up approximately equal for these two coatings because the $1000 \mu \mathrm{m}$ coating has less porosity volume given the total coating volume, which allows the temperature effects to outpace the additional volume effects. When the porosity volume is roughly constant as a percentage of total coating volume, as is the case for the 230 and $500 \mu \mathrm{m}$ coatings, then the increase in the total porosity volume with coating thickness has a greater effect than the increase in temperature.

The 31mg fuel per cycle point shows a large reduction in the porosity heat losses. The porosity losses drop because of more retarded combustion at high load to avoid knock. Later combustion timing results in lower, retarded pressure rise rates and lower peak gas temperatures because combustion is competing with the rate of volume increase at later timings. These effects drive less, cooler mass into the porosity volume, which reduce the porosity heat losses. Combustion with the $1000 \mu \mathrm{m}$ coating was retarded a further $2^{\circ}$ beyond the other $31 \mathrm{mg}$ points due to a lack of acceptable data at this load due to coating degradation, accentuating this trend and ultimately reducing the total heat rejection to the piston when compared to the $21 \mathrm{mg}$ point.
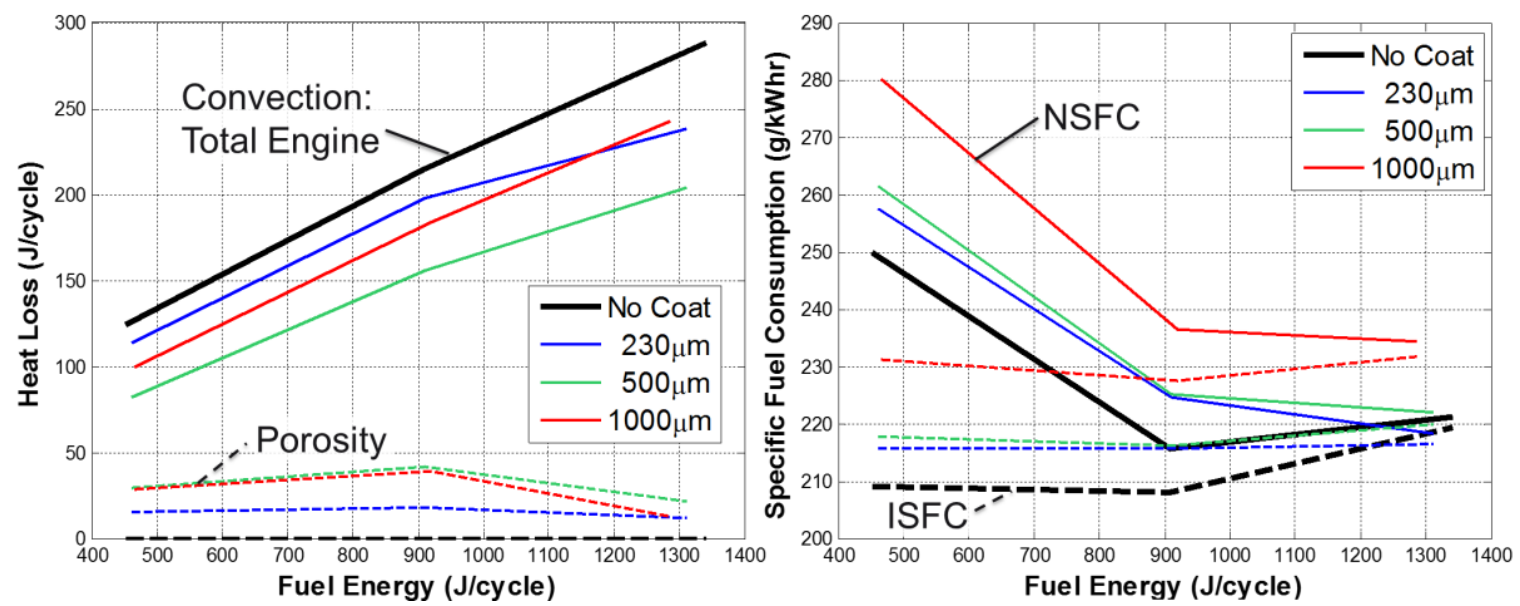

Figure 6: Coating Effects on Engine Performance

None of the coated pistons showed any efficiency improvement over the uncoated piston. The specific fuel consumption continually increased with coating thickness, although the $500 \mu \mathrm{m}$ coating performance was better than could be expected solely based on thickness. At high loads, efficiency between the un-coated piston and the 230 and $500 \mu \mathrm{m}$ coatings converged due to the reduction in porosity losses with retarded combustion. The $1000 \mu \mathrm{m}$ coating continually performed worse than the others due to porosity volume as well as slow late combustion. These observed losses from permeable porosity reflect similar observations made in the literature with respect to coatings (29) (4) and combustion deposits (30). Additionally, the thickest coating hurt volumetric efficiency by $2.6 \%$, the $500 \mu \mathrm{m}$ coating decreased it by $1.2 \%$, and the thinnest coating had no impact. Ultimately, permeable porosity introduced additional heat losses that could not be overcome by decreased convection, and must be avoided if gains in efficiency are to be achieved. 
The piston coatings were all inspected after completing the engine tests, and are shown in Figure 7 . Inspection of the $500 \mu \mathrm{m}$ piston surface after running showed considerably less discoloration around the fuel spray impingement region than the $230 \mu \mathrm{m}$ piston, but did not reveal the very large pores or large-scale flaking of the $1000 \mu \mathrm{m}$ coating. This suggests that the $500 \mu \mathrm{m}$ coating represented a robust thickness that presented a more impermeable surface to liquid fuel. The surface roughness of the $500 \mu \mathrm{m}$ piston was comparable to that of the $230 \mu \mathrm{m}$ piston in visual inspection, which implies that the greater impermeability was primarily due to thermal effects. The top surface of the $500 \mu \mathrm{m}$ coating was approximately $50^{\circ} \mathrm{C}$ hotter than the $230 \mu \mathrm{m}$ coating, which would promote liquid fuel evaporation upon impingement. This could prevent the fuel from wicking into the coating and packing the porosity with partially reacted hydrocarbons and soot, which appears to have occurred for the $230 \mu \mathrm{m}$ coating. Additionally, the surface temperature of the $500 \mu \mathrm{m}$ and $1000 \mu \mathrm{m}$ coatings exceeded $320^{\circ} \mathrm{C}$ throughout the cycle for most of the points, which was the temperature at which large deposits failed to form on the combustion chamber walls as noted by (31). This evidence lends credence to the hypothesis that the $500 \mu \mathrm{m}$ coating had better-than-expected performance due to a lack of fuel penetration, deposit formation, and overall degradation of coating integrity.

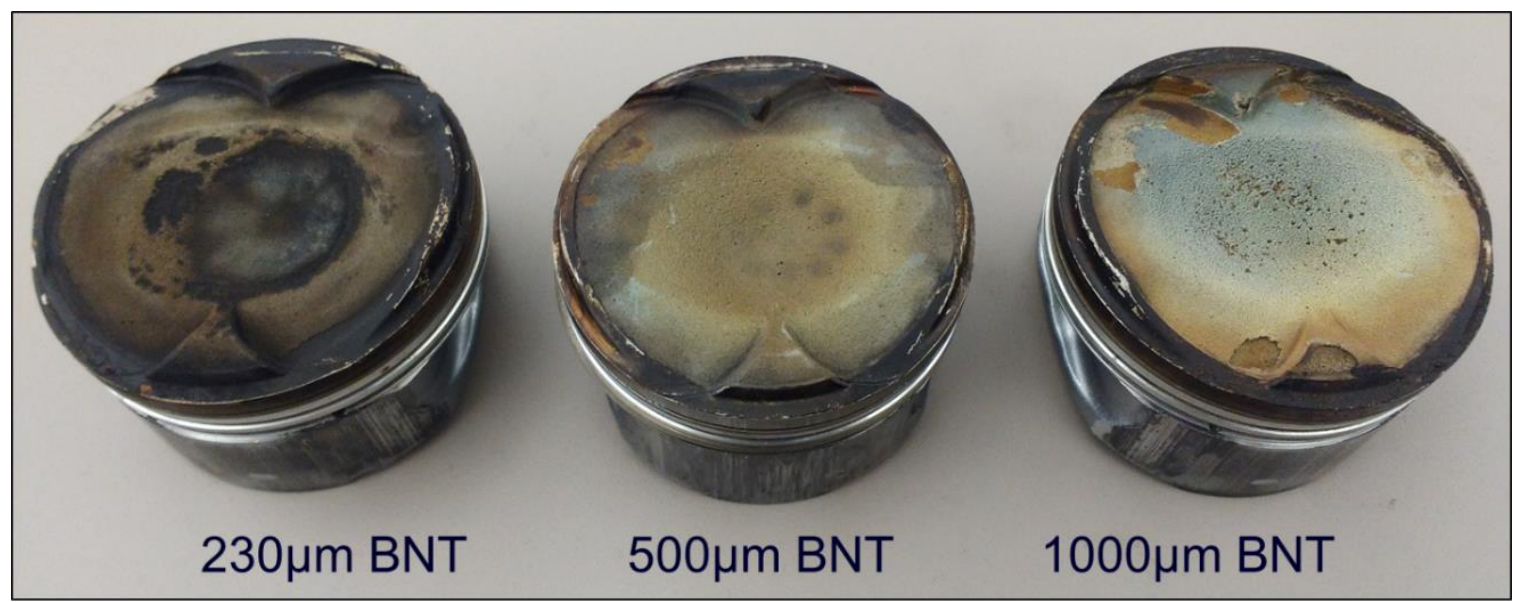

Figure 7: Piston BNT Coating Appearance Post-Testing

The $1000 \mu \mathrm{m}$ coating was the most susceptible to physical degradation because it was the thickest. The thermal gradient from top to bottom would be the greatest for this coating, and therefore the thermal stresses due to expansion and contraction would be the greatest. Additionally, the hottest piston surface will experience the greatest heat transfer to colder temperatures such as the fuel spray and the intake air flow, which will increase the shock experienced by the coating from these sources. All of the coatings showed more flaking on the intake side than on the exhaust side, but this was most pronounced with the thickest coating. It is difficult to draw firm conclusions from this dataset due to the porosity and continued degradation of some of the coatings which could have changed their properties and response to the engine environment over the course of testing.

One form of physical degradation throughout testing that was observed with the $1000 \mu \mathrm{m}$ coating is shown in Figure 8. This is not the onset of a traditional auto-ignition mode of knock; instead this is a transition from controlled spark-ignition to unintentional pre- 
ignition. The source of pre-ignition is suspected to be loose particles that broke free from the coating, got heated by combustion in previous cycles, did not leave the cylinder with the exhaust gas, and then ignited the air-fuel mixture in the next cycle. This is supported by the large pock-marks visible in the $1000 \mu \mathrm{m}$ coating surface but not in the other surfaces and by substantial scoring of the bore wall accompanied by larger gritty particles found in the ring-pack after running this piston. The particles were likely big enough that they were not ejected from the combustion chamber immediately, and resulted in hotter temperatures which could encourage more coating erosion to provide a steady source of unintentional ignition sources necessary to sustain pre-ignition at a relatively constant CA50 of $-38^{\circ}$ bTDCf. The only occurrence of the ringing pressure signature of knocking auto-ignition occurred in the 25 cycles immediately before the burn began rapidly advancing, suggesting that the increased heat transfer to the piston surface and percussive pressure waves from knock broke the first particles free from the coating where they could heat to higher temperatures in the burned gas.
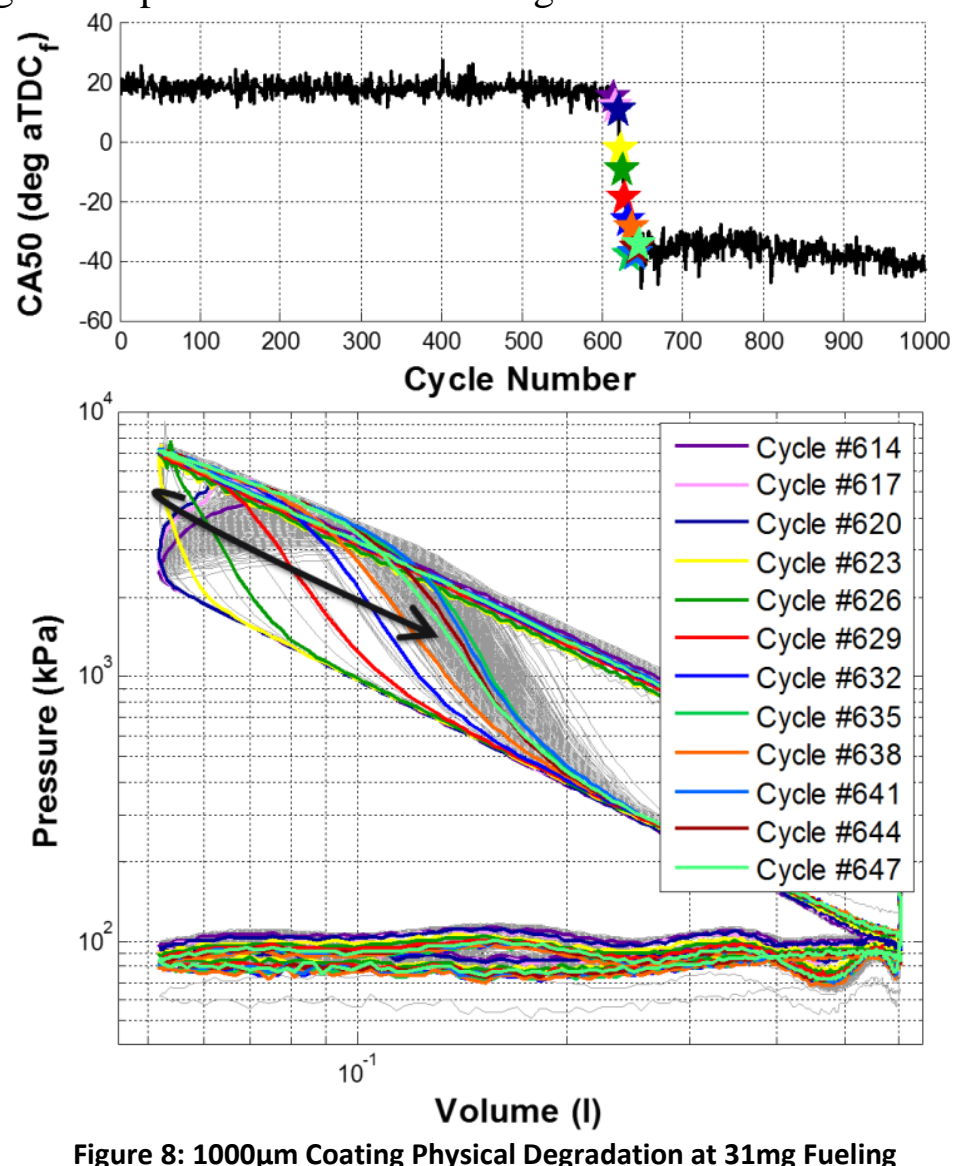

Besides the pre-ignition noted above, there were no observed trends in autoignition with the coatings. The difference in gas temperature between the un-coated case and each of the coating thicknesses is shown in Figure 9 for the $31 \mathrm{mg}$ fueling point. During the majority of the intake and compression strokes, the bulk gas temperature of all of the coatings were within $20^{\circ} \mathrm{C}$ of the uncoated case, providing a very small difference in activation energy for autoignition. The spikes in temperature just after TDC are due to slight differences in combustion phasing between each coating and the uncoated case for 
the experimental data. Effectively, the reduced compression ratio due to coating porosity was preventing an increase in bulk gas temperature despite the hotter wall surface temperature. This was born out in measured knock amplitude over a combustion timing sweep, where increasing coating thickness actually showed a reduction in knock at a given bulk combustion phasing.

Lower knock amplitudes with increasing insulation is counterintuitive, but could potentially be explained when considering the reduction in thermal stratification with hotter walls but lower compression ratio. Hotter walls will increase the local gas temperature close to the walls, but lower compression ratio will reduce the average temperature. If the walls are hot enough to drive the bulk gas temperature during intake and compression up despite a reduction in compression ratio, then what would traditionally be the coldest packets of gas near the wall will be hotter while the more central packets of gas further away from the wall will be cooler than the un-coated case. The more central packets in the higher CR, uncoated engine will still be hotter than the gas near the wall, especially after the combustion has been initiated and has further compressed the unburned gas. These packets of gas will be the most likely to cross the autoignition threshold. Therefore, it can be reasoned that the combination of a reduction in compression ratio and increase in wall temperature from these specific coatings could potentially reduce the thermal stratification and the likelihood of autoignition.
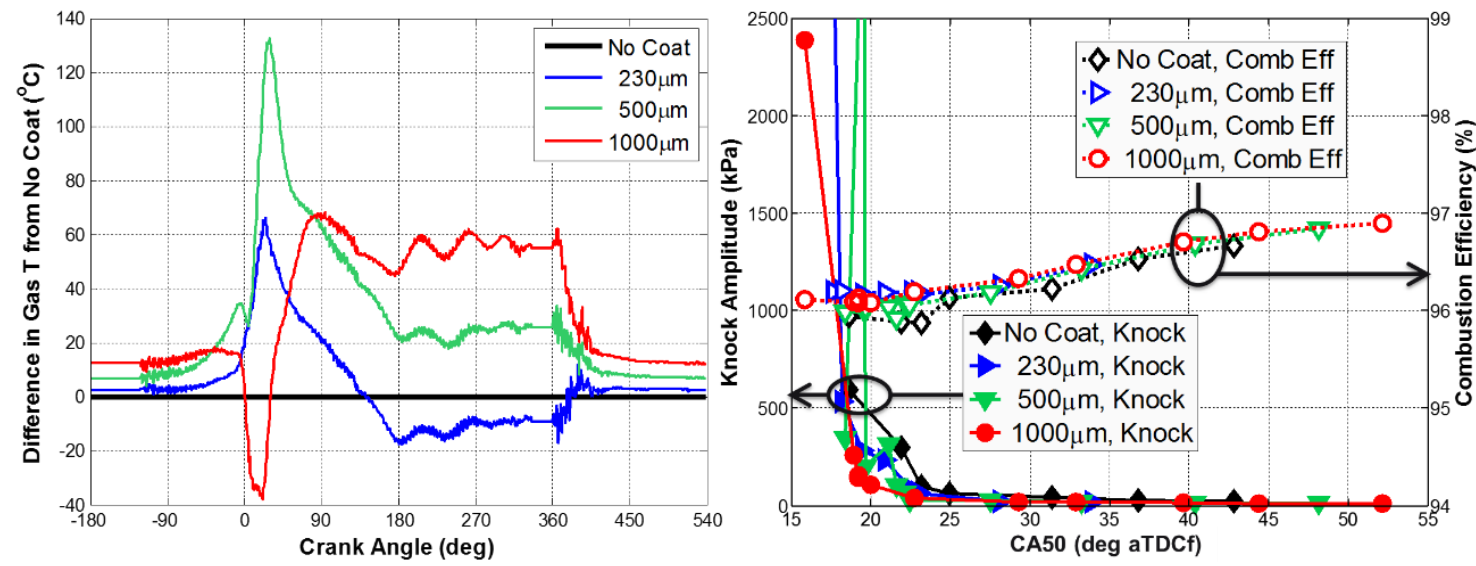

Figure 9: Difference in Gas Temperature, Knock Amplitude, and Combustion Efficiency at 31mg Fueling

Combustion efficiency tended to be slightly higher for coatings than for the un-coated baseline as well. The differences were very small, but could have been driven by the generally hotter late expansion and exhaust temperatures that accompanied a longer later burn and thermal insulation.

\section{Simulated Performance}

The effects of the coating porosity on heat losses, fuel mixing, and compression ratio all acted to confound the experimental results. To understand the individual contributions of each of these effects, the calibrated thermodynamic model was used in conjunction with the thermal model to simulate the engine with each of the coated pistons in multiple steps. The thermodynamic model did not allow for a porosity volume and the subsequent 
heat loss assumptions in the data processing routines to be applied, so the first step relies on a comparison between the experimental data with and without coatings. In all comparisons, the modeled results for the un-coated engine remained the same.

The second step in analysis was to remove the porosity heat losses by switching to the modelled results. The experimental compression ratio, combustion profile, boundary conditions, and piston thermal geometry were maintained for the various coating thicknesses. However, the energy closure multiplier from the un-coated case at the same load and combustion phasing was applied to the coated model. The rationale for this was that the energy closure multiplier should be very similar for all cases at the same load and combustion phasing as long as the wall temperature for convection and other energy loss mechanisms were being properly captured, since the convection coefficient would respond only to the combustion chamber gas properties. This was experimentally observed when comparing most of the different hardware sets at matched fueling and combustion phasing when the porosity losses were accounted for. Additionally, a comparison of the instantaneous heat flux measured at the cylinder head showed that there were minimal differences in heat transfer at this location, indicating that the incylinder thermal environment, turbulence, and boundary layer were similar, at least in the measured location. While this certainly does not mean that the conditions for convective heat transfer were identical everywhere in the chamber, especially at the piston top surface, it does suggest that there is some basis for making this assumption. Following this assumption, the largest impact on the energy closure multiplier from experimental data would be whether the heat loss from permeable porosity were accurately captured. Referring back to Figure 3, this multiplier $(\alpha)$ was consistent between the un-coated baseline and the $230 \mu \mathrm{m}$ and $1000 \mu \mathrm{m}$ coatings, with the $500 \mu \mathrm{m}$ coating consistently requiring a slightly lower multiplier that suggested it was less permeable than the others. This methodology would remove the heat losses from porosity, but retains the effects of fuel absorption and mixing due to the porosity, and the reduction in compression ratio.

Removal of the fuel absorption and mixing effects on performance in the third step entailed applying the combustion profile and boundary conditions from the non-coated experimental data to the coated thermal model, while retaining the lower compression ratio from the coated data. This assumes that the primary way the effects of fuel absorption into the porous coating are seen is through the shape and cumulative magnitude of heat release in the experimental data. The energy closure multiplier from the un-coated baseline is also applied for the same reasons as the previous paragraph. Accounting for the reduced compression ratio is accomplished by using the compression ratio from the un-coated baseline in the fourth step. In essence, the models for this step for coated cases and the baseline are identical except for the thermal piston model, which reflects the presence and thickness of the coating.

The individual effects from each of these steps are shown in Figure 10, with the difference in heat transfer (including porosity losses) between the $230 \mu \mathrm{m}$ coating and the un-coated baseline at $21 \mathrm{mg}$ fueling rate on the left, and the difference in indicated piston power on the right. This coating thickness and load were chosen for clarity, and are representative of the other thicknesses and loads. The difference in heat loss in the trace 
for the experimental data is dramatic, with a large spike around TDC due to the increasing pressure and temperature driving hot gas into the porous volume. After approximately $20^{\circ}$ aTDC, the heat loss rate in the data is lower than the un-coated baseline and the simulated results because the piston surface is hotter and the gas is cooler due to the porosity heat loss. Comparing the experimental data trace to the model without porosity heat transfer shows the net effect of the porous heat losses to be worth $7.9 \mathrm{~J}$ over the entire cycle. However, a total of $14.6 \mathrm{~J}$ was lost due to porosity heat losses alone around TDC between $-30^{\circ}$ and $15^{\circ}$ aTDC. This phasing has the greatest impact on piston indicated power because energy has already been expended to compress the gas, but additional heat losses near TDC will lower the gas pressure through the entire expansion stroke, hurting the positive energy generation by expansion. The total difference in piston indicated work due to the porosity heat losses alone amounts to a loss of $13.6 \mathrm{~J}$ each cycle.
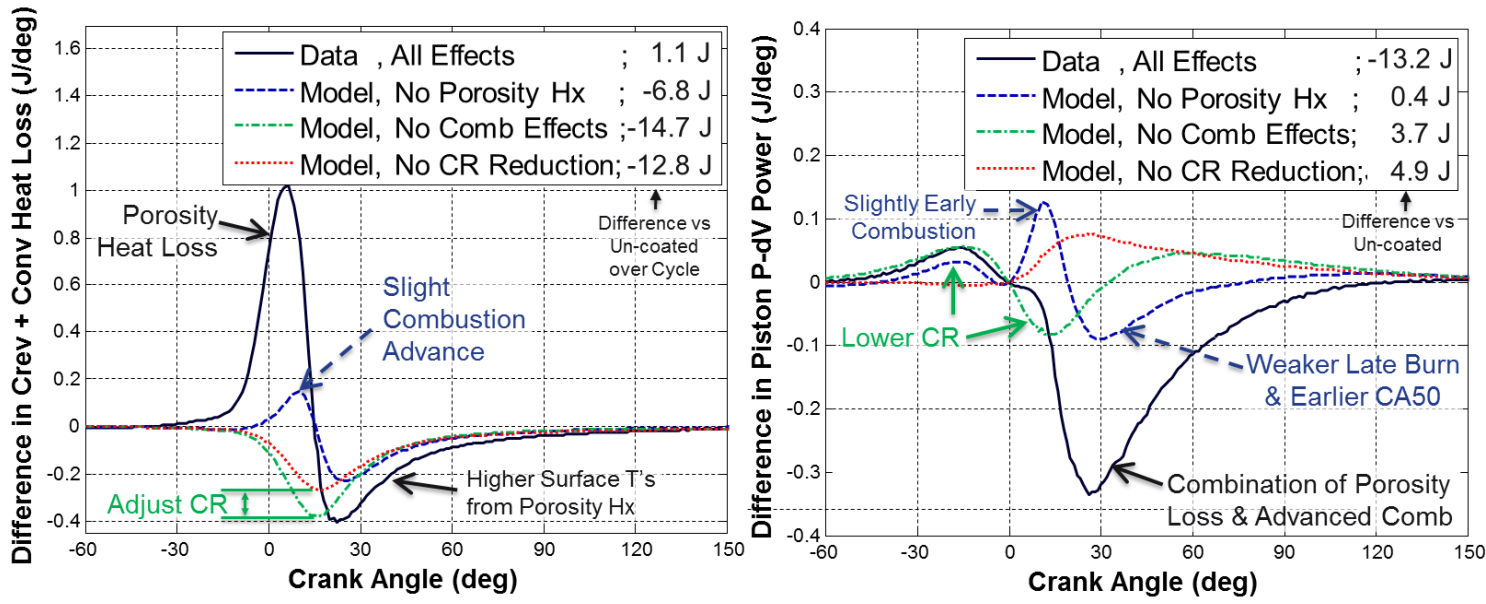

Figure 10: Individual Effects of $230 \mu \mathrm{m}$ Coating on Heat Loss and Indicated Power vs. Un-Coated Baseline

Removing the combustion effects had the same net effect on total heat losses of 7.9 $\mathrm{J} /$ cycle, but the impact on indicated work was only $3.3 \mathrm{~J} /$ cycle. The primary combustion effect was a slight CA50 retard of $0.9^{\circ}$ when removing combustion effects, which can be seen as an early positive peak in heat loss and indicated work after TDC of the "Model, No Porosity Hx" trace in comparison to the "No Comb Effects" line. The more advanced combustion causes pressure and temperature to increase earlier in the cycle when the volume is smaller, resulting in higher gas temperatures and pressures for the early part of the cycle. In this instance, since the additional heat loss early in the expansion stroke was accompanied by an increase in cylinder pressure, the effects on indicated work were minimized. A peak in heat transfer early is usually accompanied by less heat transfer later in expansion since the gas will be cooler, but the differences in these traces beyond $20^{\circ}$ are primarily due to the heat release shape for the final $4 \%$ of fuel energy. Despite having a more retarded CA50, combustion for the un-coated engine was considerably faster towards the end, having reached its final value by $40^{\circ}$ aTDC. Late combustion with the permeable coating was dragged out until the exhaust valve opened, which prevented the piston from extracting as much work from the last $30 \mathrm{~J}$ of fuel energy. 
The last step was to remove the compression ratio difference observed in the coated engine data. Increasing the compression ratio from 11.7 to 12.0 while holding everything else constant results in a smaller reduction in heat loss from the coating since the gas temperature was higher at 12.0 CR. Additionally, more work was required for compression, shown as a reduction in the positive indicated work difference prior to TDC. All of this additional compression work and more was recovered during expansion with the thermal barrier coatings at the higher compression ratio, providing the most relative and absolute benefit in indicated work.
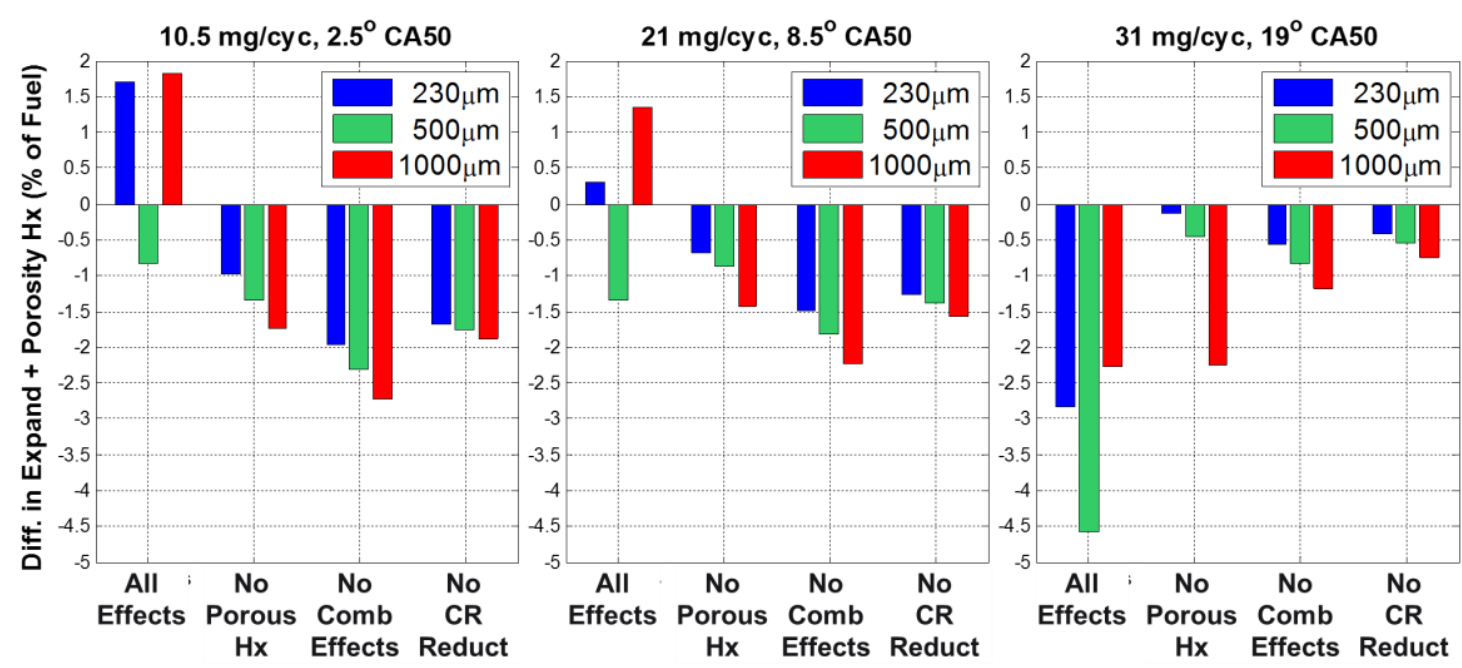

Figure 11: Difference in Expansion plus Porosity Heat Transfer from Un-coated Baseline

The total heat losses from porosity and convection during the expansion stroke are plotted for all cases and loads in Figure 11. It is clear that the $500 \mu \mathrm{m}$ coating was experiencing lower total heat losses in the experimental data ("All Effects") than the other coatings, as suggested previously by the difference in the energy closure multiplier for this coating. Otherwise, the effects of porosity heat losses were the largest deviation from expected behavior, especially when CA50 was near TDC. At the $31 \mathrm{mg}$ fueling point when porosity heat losses were minimal, all three coatings did exhibit 10 to $20 \%$ lower heat losses than the baseline, although the baseline likely had higher convection losses than the coated cases at this load due to the higher knock amplitude. Removing the combustion profile effects consistently decreased heat losses by 5 to $8 \mathrm{~J}$, while increasing the compression ratio to the baseline level increased the heat losses by roughly $3 \mathrm{~J}$. All of the modeled results showed the expected trend of decreasing heat losses with coating thickness. Once the coating thickness was the only difference between the modeled results, all three coating thicknesses decreased heat losses by similar amounts. This was because the thinnest coating was already $77 \%$ of the critical depth $1 \%$ (1), which allowed it to have the same amount of temperature swing as the thicker coatings. Similarly, the coatings had the greatest effect at the $21 \mathrm{mg}$ fueling point, since the combination of sufficient fuel energy and earlier combustion timing enabled the most temperature swing coupled with the hottest gasses. 

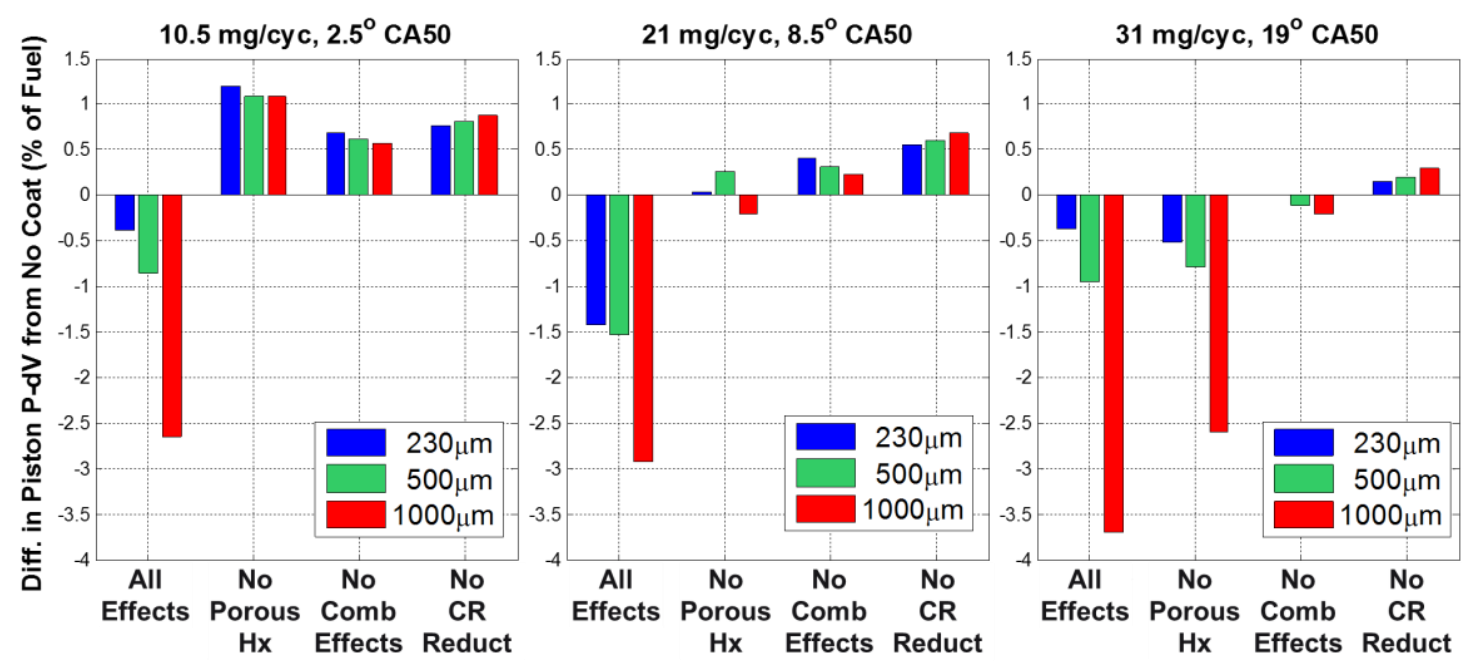

Figure 12: Difference in Indicated Piston Work from Un-coated Baseline

The impact of the change in heat losses for each of these configurations on piston indicated work is shown in Figure 12. Porosity heat losses had the largest impact on indicated work at the lowest two loads, while their magnitude was diminished and the combustion profile impacts dominated at the highest load. Additionally, the reduction in compression ratio due to porosity in thicker coatings more than offset the benefits of higher surface temperature. Furthermore, the presence of fully developed temperature swing enabled all three coatings to have a similar level of indicated improvement at low and mid loads. The importance of reducing heat losses at the highest load was reduced because of the retarded combustion phasing, leaving less change in volume after the heat loss reduction for extracting energy from the gas. A larger portion of the improvement in indicated work, therefore, is derived from the reduction in throttling losses with hotter surface temperature during the intake stroke, which favors coating thickness.

\section{Summary and Conclusions}

The interplay of many processes related to the presence of coatings besides their thermal properties tends to muddy the results of experimentation. Effects from permeable porosity heat losses, fuel absorption, and a reduction in compression ratio all confounded the analysis, requiring careful consideration to draw conclusions.

- Porous heat losses remove energy and fuel mass from the combustion chamber near TDC and throughout the combustion process when they can be the most beneficial, having a severely negative impact on indicated work.

- Utilization of the thermal engine structure model coupled with assumptions on the permeable porosity heat losses allowed for analysis of experimental data using observed engine properties without unreasonable results.

- Earlier combustion phasings near or prior to TDC suffer the worst porous heat losses due to the large mass flows of hot gas generated by compression and 
combustion pressure; late combustion phasing avoids these losses but is generally sub-optimal for efficiency

- Lengthened heat release tails were observed with the coatings, indicating fuel was trapped within or on the surface of the coating and effectively prevented from combusting until much later in the cycle.

- Porosity heat losses impacted indicated work most severely, followed by combustion profile effects, then by reduced compression ratio from permeable porosity

- Successful implementation of temperature-swing enabling insulation requires negligible permeable porosity, necessitating a way of sealing the porosity from combustion gasses.

\section{References}

1. Analysis of the Effects of Wall Temperature Swing on Reciprocating Internal Combustion Engine Processes. Andruskiewicz, P., Najt, P., Durrett, R., Biesboer, S., Schaedler, T., Payri, R. s.l. : Submitted to the International Journal of Engine Research, 2017.

2. Kosaka, H.,Wakisaka, Y., Nomura, Y., Hotta, Y., Koike, M., Nakakita, K., Kawaguchi, A. Concept of "Temperature Swing Heat Insulation" in Combustion Chamber Walls, and Appropriate Thermo-Physical Properties for Heat Insulation Coat. Warrendale, PA : SAE 2013-01-0274, 2013.

3. Kogo, T., Hamamura, Y., Nakatani, K., Toda, T., Kawaguchi, A., Shoji, A. High Efficiency Diesel Engine with Low Heat Loss Combustion Concept - Toyota's Inline 4Cylinder 2.8-Liter ESTEC 1GD-FTV Engine. Warrendale, PA : SAE 2016-01-0658, 2016.

4. Wakisaka, Y., Inayoshi, M., Fukui, K., Kosaka, H., Hotta, Y., Kawaguchi, A., Takada, N. Reduction of Heat Loss and Improvement of Thermal Efficiency by Application of "Temperature Swing" Insulation to Direct-Injection Diesel Engines. Warrendale, PA : SAE 2016-01-0661, 2016.

5. Performance and Emission Characteristics of a low heat rejection spark ignited engine fuelled with E20. Kumar, C., Nagarajan, G. s.l. : Joural of Mechanical Science and Technology, 2012, Vols. 26 (4), 1241-1250.

6. The Impact of a Magnesium Zirconate Thermal Barrier Coating on Homogeneous Charge Compression Ignition Operational Variability and the Formation of Combustion Chamber Deposits. Hoffman, M., Lawler, B., Guralp, O., Najt, P., Filipi, Z. s.l. : International Journal of Engine Research, 2015, Vols. 16 (8), 968-981.

7. Kamo, R., Bryzik, W. Adiabatic Turbocompound Engine Performance Prediction. Warrendale, PA : SAE 780068, 1978.

8. Woschni, G., Spindler, W., Kolesa, K. Heat Insulation of Combustion Chamber Walls - A Measure to Decrease the Fuel Consumption of IC Engines? Warrendale, PA : SAE 870339, 1987. 
9. Havstad, P., Garwin, I., Wade, W. A Ceramic Insert Uncooled Diesel Engine. Warrendale, PA : SAE 860447, 1986.

10. Timoney, S., Flynn, G. A Low Friction, Unlubricated SiC Diesel Engine. Warrendale, PA : SAE 830313, 1983.

11. Morel, T., Fort, E.F., Blumberg, P.N. Effect of Insulation Strategy and Design

Parameters on Diesel Engine Heat Rejection and Performance. Warrendale, PA : SAE 850506, 1985.

12. Furuhama, S., Enomoto, Y.,. Heat Transfer into Ceramic Combustion Wall of Internal Combustion Engines. Warrendale, PA : SAE 870153, 1987.

13. Sudhakar, V. Performance Analysis of Adiabatic Engine. Warrendale, PA : SAE 840431, 1984.

14. Bryzik, W. and Kamo, R. TACOM/Cummins Adiabatic Engine Program. Warrendale, PA : SAE 830314, 1983.

15. Wallace, F., Way, R., Vollmert, H. Effect of Partial Suppression of Heat Loss to Coolant on the High Output Diesel Engine Cycle. Warrendale, PA : SAE 790823, 1979.

16. Way, R., Wallace, F. Results of Matching Calculations for Turbocharged and Compound Engines with Reduced Heat Loss. Warrendale, PA : SAE 790824, 1979. 17. Wallace, F., Kao, T., Alexander, W., Cole, A., Tarabad, M. Thermal Barrier Pistons and Their Effect on the Performance of Compound Diesel Engine Cycles. Warrendale, PA : SAE 830312, 1983.

18. Morel, T., Keribar, R. and Blumberg, P. Cyclical Thermal Phenomena in Engine Combustion Chamber Surfaces. Warrendale, PA : SAE 850360, 1985.

19. Miyairi, Y. Computer Simulation of an LHR DI Diesel Engine. Warrendale, PA : SAE 880187, 1988.

20. Assanis, D., Badillo, E. Transient Heat Conduction in Low-Heat-Rejection Engine Combustion Chambers. Warrendale, PA : SAE 870156, 1987.

21. Kamo, R., Assanis, D., Bryzik, W. Thin Thermal Barrier Coatings for Engines. Warrendale, PA : SAE 890143, 1989.

22. Applied Thin Films Inc. NanoEngineered Thermal Barrier Coatings. Evanston, Il. : atfinet.com, 2011.

23. Woschni, G. A Universally Applicable Equation for the Instantaneous Heat Transfer Coefficient in the Internal Combustion Engine. s.1. : SAE Transactions, Vol. 76, 3065, 1967.

24. Namazian, M., Heywood, J. Flow in the Piston-Cylinder-Ring Crevices of a SparkIgnition Engine: Effect on Hydrocarbon Emissions, Efficiency, and Power. Warrendale, PA : SAE 820088, 1982.

25. Guralp, O., Najt, P., Filipi, Z. Method for Determining Instantaneous Temperature at the Surface of Combustion Chamber Deposits in an HCCI Engine. Vancouver, BC, Canada : ASME ICEF2012-92188, 2012.

26. Chang, J., Guralp, O., Filipi, Z., Assanis, D., Kuo, T., Najt, P., Rask, R. New Heat Transfer Correlation for an HCCI Engine Derived from Measurements of Instantaneous Surface Heat Flux. Warrendale, PA : SAE 2004-01-2996, 2004.

27. Yang, L., Hamada, A., Ohtsubo, K. Engine Valve Temperature Simulation System. Warrendale, PA : SAE 2000-01-0564, 2000.

28. Wisniewski, T. Experimental Study of Heat Transfer on Exhaust Valves of 4C90

Diesel Engine. Warrendale, PA : SAE 981040, 1998. 
29. Assanis, D., Wiese, K., Schwarz, E., Bryzik, W. The Effects of Ceramic Coatings on Diesel Engine Performance and Exhaust Emissions. Warrendale, PA : SAE 910460, 1991.

30. Anderson, C., Prakash, C. The Effects of Variable Conductivity on Unsteady Heat Transfer in Deposits. Warrendale, PA : SAE 850048, 1985.

31. Nakic, D., Assanis, D., White, R. Effect of Elevated Piston Temperature on Combustion Chamber Deposit Growth. Warrendale, PA : SAE 940948, 1994. 